\title{
Frazil dynamics and precipitation in a water column with depth-dependent supercooling
}

\author{
By PAUL R. HOLLAND AND DANIEL L. FELTHAM \\ Centre for Polar Observation and Modelling, Department of Space and Climate Physics, \\ University College London, WC1E 6BT, UK \\ p.holland@cpom.ucl.ac.uk
}

(Received 21 April 2004 and in revised form 14 October 2004)

\begin{abstract}
When seawater becomes supercooled, collections of small ice crystals, known as frazil ice, form and grow. A model of frazil ice dynamics is presented that deals explicitly with the buoyant settling of frazil crystals onto an overlying surface. This yields further insight into transport associated with the ice pump mechanism, whereby ice is melted at depth and transferred to a shallower location as a result of the pressure variation of seawater's freezing temperature. The model is applied to a vertical cross-section through an Ice Shelf Water plume beneath Filchner-Ronne Ice Shelf, Antarctica, and helps to elucidate the depth-variation in its properties for the first time, as well as predicting the precipitation rate of frazil crystals. The model predicts that frazil ice should be preferentially located in a narrow layer near the ice shelf base as a result of the maximum supercooling there and an influx of crystals rising under their own buoyancy. The deposition of these crystals onto the ice shelf is governed by the balance between crystal rising and turbulent transfer of frazil away from the shelf, which is investigated in some detail.
\end{abstract}

\section{Introduction}

The 'ice pump' is a heat engine which melts ice at depth and deposits it at a shallower location (Lewis \& Perkin 1983, 1986). If water at the surface freezing temperature sinks, it has the potential to melt ice at depth owing to the decrease in the freezing temperature of seawater with increasing pressure $\left(\approx-7.53 \times 10^{-3}{ }^{\circ} \mathrm{C} \mathrm{bar}^{-1}\right)$. Conversely, if meltwater released at depth rises, it may become supercooled. Any sufficiently thick body of ice that is in contact with seawater could therefore initiate an ice pump. If infinitesimal melting occurs at depth, the resulting meltwater rises owing to its buoyancy, supercooling causes ice formation to occur, and brine rejection from this freezing may induce a compensating downwards flow at some distance from the ice, leading to more melting at depth and a self-sustaining overturning circulation (Lewis \& Perkin 1986).

The ice pump is thought to be particularly important in redistributing ice mass under large ice shelves (Williams, Warner \& Budd 1998; Holland, Jacobs \& Jenkins 2003; Joughin \& Padman 2003; Smedsrud \& Jenkins 2004). Probably the best-known example of this is the Filchner-Ronne Ice Shelf (FRIS), where sea ice formation in the nearby Weddell Sea generates High-Salinity Shelf Water (HSSW), which sinks down the sloping sea bed into the cavity beneath FRIS and melts ice near its grounding line at depths of up to $2 \mathrm{~km}$ (figure 1) (Joughin \& Padman 2003). The meltwater forms a turbulent rising plume of relatively fresh Ice Shelf Water (ISW), 


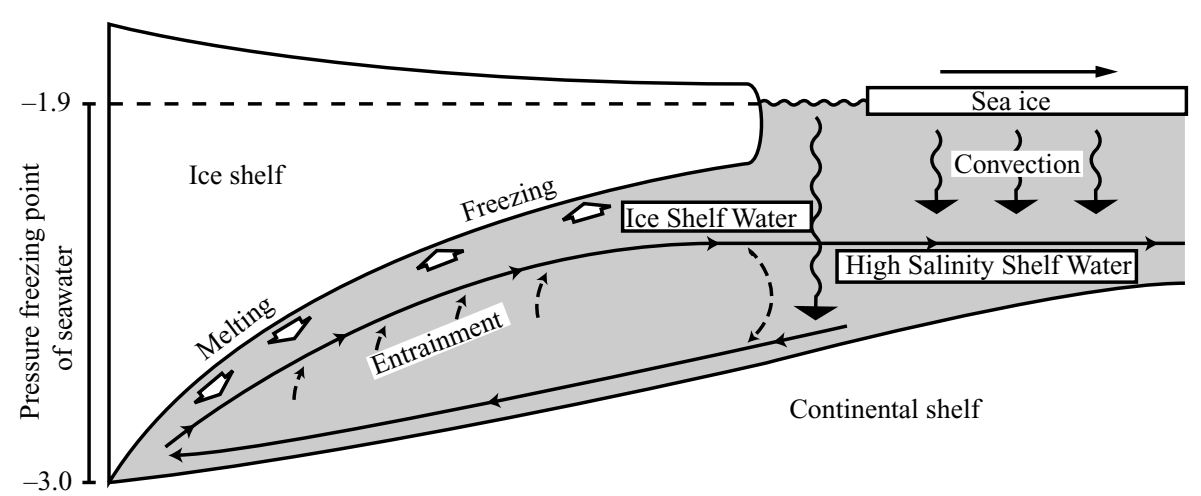

FIGURE 1. Schematic diagram of the ice pump mechanism operating under an ice shelf. The formation of sea ice generates High-Salinity Shelf Water, which sinks down the continental shelf and melts the ice shelf at its grounding line. The fresh meltwater released initiates an Ice Shelf Water plume, which becomes supercooled as it rises and thus deposits ice at shallower depths.

and the consensus of current work is that this plume becomes supercooled as it rises, causing frazil ice formation that deposits at the ice shelf base to form marine ice that can be over $300 \mathrm{~m}$ thick (Thyssen, Bombosch \& Sandhäger 1993; Sandhäger, Vaughan \& Lambrecht 2004). The ice pump may also act on ridged sea ice (Lewis \& Perkin 1986; Jeffries et al. 1995), but the smaller vertical extent of this ice means that the mechanism is unlikely to dominate basal phase changes.

Lewis \& Perkin's original consideration of the ice pump concentrated solely on direct melting and freezing at the ice-water interface, concluding that the rate of an ice pump is limited by the maximum melt rate (which is moderated by the stabilizing effect of meltwater on the water column) and the rate at which the meltwater is transported to the freezing zone (Lewis \& Perkin 1986). However, the possible formation of frazil ice crystals in the rising meltwater plume complicates the analysis of ice pumps considerably.

Frazil ice crystals are tiny (radii of $0.01-10 \mathrm{~mm}$ ) disk-shaped crystals of ice that form in a turbulent body of water when it becomes supercooled and require continuous turbulence to stay in suspension (Daly 1994a). Frazil ice formation is probably the main mechanism by which the rising meltwater of a turbulent ISW plume refreezes in a different location; it is much more efficient at quenching supercooling than direct freezing because frazil clouds have a large surface area over which phase changes can occur. Formation of suspended frazil ice also increases the buoyancy of a rising plume, causing it to accelerate and thereby increasing the rate of supercooling and frazil formation; this feedback mechanism results in plumes that are highly sensitive to changes in the topography of the ice alongside which they are ascending (Jenkins \& Bombosch 1995). In addition, the fact that frazil ice forms a major component of the ice pump implies that the ice pump rate will be critically dependent upon the location and rate of frazil precipitation, which is itself controlled by plume dynamics and the growth of frazil ice (Smedsrud \& Jenkins 2004).

Frazil ice formation in ISW plumes has so far only been modelled in the onedimensional depth-averaged models of Jenkins \& Bombosch (1995, hereinafter referred to as JB) and Smedsrud \& Jenkins (2004, hereinafter referred to as SJ), who postulated the paths that the plumes take. While their results are in good spatial agreement with basal melting and freezing rates inferred from observation (Joughin \& Padman 2003), the predicted deposition of basal ice seems to be systematically lower 
than the inferred results by up to $2 \mathrm{~m}$ year $^{-1}$. It seems likely that the frazil formation and deposition predictions of these models would benefit from the inclusion of depthvariation and horizontal Coriolis forces. Variation in supercooling over the depth of the plume as a result of the decrease in freezing temperature with depth should influence both the total frazil growth rate and the position at which the plume makes the transition between supercooled and superheated states. If the plume is perfectly well mixed then, as it ascends, its upper edge will become supercooled first, will always have the largest supercooling, and will become superheated again last.

In addition to these plume models, a range of general circulation models (GCMs) have been applied to the ice pump mechanism in the cavity beneath FRIS (Determann \& Gerdes 1994; Gerdes, Determann \& Grosfeld 1999; Jenkins \& Holland $2002 a, b)$. These, however, have focused on the modelling of direct melting and freezing at the ice shelf base (Holland \& Jenkins 1999; Jenkins, Hellmer \& Holland 2001) and, as yet, no GCM has incorporated or parameterized frazil ice or its deposition.

In $\S 2$ of this paper, a general multiple-size-class frazil dynamics model is modified in order to study the frazil deposition phase of the ice pump mechanism. Particular attention is paid to the specification of frazil ice precipitation and a model that explicitly features the near-shelf balance between crystal rising and turbulent mixing is formulated. In $\S 3$, the model is applied to a 'well-mixed' domain in which the model is tested for sensitivity to initial conditions and the number of crystal size classes. Finally, as an example application of the model, in $\S 4$, a vertical cross-section of an ISW plume from SJ is modelled in order to examine frazil ice deposition from a different perspective to that of previous work.

\section{Mathematical model and simplifications}

In this section, the mathematical model governing heat transfer and frazil ice evolution and precipitation is described.

\subsection{Frazil governing equations}

Frazil-laden water is considered to be a two-component mixture of ice and seawater that is treated as a homogeneous fluid with averaged properties (JB). The density is determined by the mixture density $\rho_{m}$ :

$$
\rho_{m}=\rho+C\left(\rho_{I}-\rho\right),
$$

where $\rho_{I}=920 \mathrm{~kg} \mathrm{~m}^{-3}$ is the ice density and the seawater density $\rho$ is described by a simple linearized equation of state:

$$
\rho=\rho_{0}\left[1+\beta_{S}\left(S-S_{0}\right)-\beta_{T}\left(T-T_{0}\right)\right],
$$

where $\rho_{0}=1030 \mathrm{~kg} \mathrm{~m}^{-3}, T_{0}=-2.0^{\circ} \mathrm{C}$ and $S_{0}=34.5 \mathrm{psu}$ are reference density, temperature and salinity, respectively, and $\beta_{S}=7.86 \times 10^{-4} \mathrm{psu}^{-1}$ and $\beta_{T}=3.87 \times 10^{-5}{ }^{\circ} \mathrm{C}^{-1}$ are expansion coefficients. The ice concentration $C$ is the total ice volume per unit mixture volume and is distributed between $N_{i c e}$ size classes such that $C=\sum_{i=1}^{N_{i c e}} C_{i}$. Frazil crystals are treated as circular disks and each class is defined by a fixed crystal radius so that growth or melting results in a transfer of mass between classes.

Salinity variations play only a small role in the thermodynamics of an ISW plume. Changes in salinity due to frazil growth and melting are tiny, because $C$ is generally much smaller than unity, and their effect on the freezing temperature is smaller still. Therefore, salinity is held constant throughout this paper. 
Applying the Boussinesq approximation to the water fraction (setting $\rho=\rho_{0}$ ) and denoting the new mixture density $\rho_{m}^{*}=\rho_{0}+C\left(\rho_{I}-\rho_{0}\right)$, we obtain a conservation of mass equation for the mixture:

$$
\frac{\partial \rho_{m}^{*}}{\partial t}+\nabla \cdot\left(\rho_{m}^{*} \boldsymbol{u}\right)=0 .
$$

Bearing in mind the effects of buoyant rising and turbulent mixing of frazil crystals, we formulate mass balance equations for the ice and water fractions:

$$
\begin{gathered}
\frac{\partial\left(\rho_{I} C\right)}{\partial t}+\nabla \cdot\left(\rho_{I} C \boldsymbol{u}\right)+\sum_{i=1}^{N_{\text {ice }}} \rho_{I} w_{i} \frac{\partial C_{i}}{\partial z}=\nabla \cdot\left(\mu_{T} \nabla C\right)-\rho_{0} w^{\prime} \\
\frac{\partial}{\partial t}\left[\rho_{0}(1-C)\right]+\nabla \cdot\left[\rho_{0}(1-C) \boldsymbol{u}\right]+\sum_{i=1}^{N_{i c e}} \rho_{I} w_{i} \frac{\partial\left(1-C_{i}\right)}{\partial z}=\nabla \cdot\left[\mu_{T} \nabla(1-C)\right]+\rho_{0} w^{\prime}
\end{gathered}
$$

Here, $w_{i}$ is the frazil crystal rising velocity for each size class, $z$ is the vertical coordinate (positive upwards), $\mu_{T}$ is the turbulent eddy coefficient for both fractions, and we shall treat the turbulent eddy diffusivity $v_{T} \equiv \mu_{T} / \rho_{0}=\mu_{T} / \rho_{I}$. We define $w^{\prime}$ to be the net discharge of water per unit mixture volume owing to melting of frazil ice, and it is therefore negative during ice formation (JB). Note that addition of the mass balance equations for the ice and water fractions, (2.4) and (2.5), yields the mass balance of the mixture (2.3).

Following JB, we adopt the Boussinesq approximation for the mixture on the basis that frazil concentrations are always small so that

$$
\nabla \cdot \boldsymbol{u}=0 .
$$

The balance equation for the volume concentration of the $i$ th crystal class, using (2.6), may be written

$$
\frac{\partial C_{i}}{\partial t}+\boldsymbol{u} \cdot \nabla C_{i}+w_{i} \frac{\partial C_{i}}{\partial z}=\nabla \cdot\left(v_{T} \nabla C_{i}\right)+S_{i}
$$

where $v_{T}$ is the turbulent eddy diffusivity of frazil ice. $S_{i}$ represents the interaction terms between class $i$ and other frazil size classes and therefore is a component of the release or uptake of water owing to the phase changes represented by the final term on the right-hand side of (2.4).

The frazil rise velocity $w_{i}$ relative to the moving fluid is approximated by frazil's buoyant drift velocity in still water (Gosink \& Osterkamp 1983):

$$
w_{i}^{2}=\frac{4\left(\rho_{0}-\rho_{I}\right) g a_{r} r_{i}}{\rho_{0} C_{i}^{d}},
$$

where $g=9.81 \mathrm{~m} \mathrm{~s}^{-2}$ is the magnitude of acceleration due to gravity, $a_{r}$ is the aspect ratio of a frazil disk and $r_{i}$ is its radius. In this expression $C_{i}^{d}$ is the crystal drag coefficient, which is calculated iteratively from the disk Reynolds number (JB). It is assumed that the frazil disks have a fixed aspect ratio such that the disk thickness is $t_{i}=2 a_{r} r_{i}$, where $a_{r}=1 / 50$, as adopted by SJ.

\subsection{Temperature equation}

To derive an equation for the temperature of the water fraction of the frazil-seawater mixture, we proceed from the conservation of water-fraction heat per unit volume of 
mixture, setting $\rho=\rho_{0}$ and $c_{0}=3974 \mathrm{~J} \mathrm{~kg}^{-1}{ }^{\circ} \mathrm{C}^{-1}$ :

$$
\frac{\partial}{\partial t}[(1-C) T]+\nabla \cdot[(1-C) \boldsymbol{u} T]+T \frac{\rho_{I}}{\rho_{0}} \sum_{i=1}^{N_{i c e}} w_{i} \frac{\partial\left(1-C_{i}\right)}{\partial z}=\nabla \cdot\left(v_{T} \nabla[(1-C) T]\right)-\frac{Q_{T}}{\rho_{0} c_{0}},
$$

where $Q_{T}$ is the heat sink per unit mixture volume owing to the melting of frazil ice $\left(\mathrm{W} \mathrm{m}^{-3}\right)$. In this analysis, the turbulent diffusivities of heat and the water fraction are assumed to equal that of frazil ice and are taken to be constant. Applying (2.5), we obtain an expression of heat conservation in the water fraction per unit volume of water

$$
(1-C) \frac{\partial T}{\partial t}+(1-C) \boldsymbol{u} \cdot \nabla T=(1-C) \nabla \cdot\left(v_{T} \nabla T\right)-2 v_{T} \nabla T \cdot \nabla C-w^{\prime} T-\frac{Q_{T}}{\rho_{0} c_{0}},
$$

where the fourth term on the right-hand side represents the inter-phase transport of seawater sensible heat energy due to mass transfer during melting or freezing. The heat $\operatorname{sink} Q_{T}$ is formulated as follows:

$$
Q_{T}=\rho_{0} c_{0}(1-C) \sum_{k=1}^{n} \gamma_{T k}^{c}\left(T-T_{c}\right) \alpha_{k}-\rho_{0} c_{0} w^{\prime} T_{c},
$$

where $n$ is the number of ice crystals of all sizes in the unit volume considered, $\gamma_{T k}^{c}$ is the heat transfer coefficient $\left(\mathrm{m} \mathrm{s}^{-1}\right)$ and $\alpha_{k}$ is the surface area per unit volume $\left(\mathrm{m}^{-1}\right)$ associated with the $k$ th frazil disk, and $T_{c}$ is the temperature of all frazil crystals. The first term in this expression is the diffusion of heat toward or away from crystal surfaces and the second term is the inter-phase transport of meltwater heat energy due to mass transfer during a phase change. It should be noted that this definition of $Q_{T}$ differs from that of JB.

Balancing diffusion of heat within the water with the latent heat release or uptake during the phase change associated with each crystal in a unit volume, we obtain

$$
(1-C) \sum_{k=1}^{n} \gamma_{T k}^{c}\left(T-T_{c}\right) \alpha_{k}=\frac{\mathscr{L} w^{\prime}}{c_{0}}
$$

where $\mathscr{L}=3.35 \times 10^{5} \mathrm{~J} \mathrm{~kg}^{-1}$ is the latent heat of ice fusion. It is also assumed that $1-C \approx 1$ and the crystal temperature is the equilibrium freezing temperature, $T_{f}=a S+b+c \zeta$, where $\zeta$ is the depth below mean sea level, $a=-0.0573{ }^{\circ} \mathrm{C} \mathrm{psu}^{-1}$, $b=0.0832^{\circ} \mathrm{C}$, and $c=-7.61 \times 10^{-4}{ }^{\circ} \mathrm{C} \mathrm{m}^{-1}$.

Considering $C \ll 1$ also allows us to neglect the fourth term in (2.10); because of its extra factor of $C$, this term will always be negligible compared to the other turbulent diffusion term (the third term) after non-dimensionalization. Combining (2.10), (2.11) and (2.12) then leads to the final equation governing the water fraction temperature

$$
\frac{\partial T}{\partial t}+\boldsymbol{u} \cdot \nabla T=\nabla \cdot\left(v_{T} \nabla T\right)+w^{\prime}\left(T_{f}-T-\frac{\mathscr{L}}{c_{0}}\right) .
$$

The second term on the right-hand side of (2.13) can be regarded as the change in temperature of a fixed volume of the water fraction due to a frazil crystal phase change and the accompanying input or uptake of meltwater. 


\subsection{Frazil interaction model}

The frazil ice dynamics are encapsulated in the size-class interaction terms, which appear as $S_{i}$ in (2.7). In this model, inter-class transfers are assumed to occur by three processes: frazil growth, melting and secondary nucleation. All three processes result in transfer of mass between size classes within the ice fraction of the mixture, but growth and melting also result in a mass transfer between ice and water fractions. $S_{i}$ is formulated as follows:

$$
S_{i}=-\frac{\rho_{0}}{\rho_{I}} w_{i}^{\prime}+N_{i}
$$

because $w^{\prime}=\sum_{i=1}^{N_{i c e}} w_{i}^{\prime}$ is the water volume change due to melting and freezing while $N_{i}$ is a rate of ice volume change representing secondary nucleation (both per unit mixture volume).

Freezing or melting is modelled by the transfer of a certain number of ice crystals from class $i$ to the size class above $(i+1)$ or below $(i-1)$. For example, ice growth transfers mass to the next largest size class, so $C_{i}$ will be increased by growth of class $i-1$ and decreased by growth of class $i$. Therefore, the rate of change of ice concentration in each size class is determined by the difference in growth (melting) rates between that class and the class below (above).

Transfer processes between classes must be consistent with the movement of crystals of the appropriate volume (SJ). In order for growth or melting to transfer a single frazil crystal out of a class, the predicted volume change of the whole class must total the difference in volume between a crystal in the source class and a crystal in the target class. For example, if $v_{i}$ is the volume of an $i$ th-class crystal, growth of all crystals in class $i$ must increase $C_{i}$ by $\Delta v_{i}=v_{i+1}-v_{i}$ to transfer one crystal to class $i+1$. A crystal of volume $v_{i}$ is removed from class $i$ and a crystal of volume $v_{i+1}$ is introduced into class $i+1$, with a mass transfer of $\Delta v_{i}$ from the water fraction to the ice fraction.

Following these principles, and formulating growth $\left(G_{i}\right)$, melting $\left(M_{i}\right)$ and secondary nucleation $\left(N_{i}\right)$ terms as rates of ice volume change per unit mixture volume $\left(\mathrm{s}^{-1}\right)$, we obtain

$$
S_{i}=\frac{v_{i}}{\Delta v_{i-1}}\left[(1-H) M_{i}+H G_{i-1}\right]-\frac{v_{i}}{\Delta v_{i}}\left[(1-H) M_{i+1}+H G_{i}\right]+N_{i},
$$

where $v_{0}=v_{N_{i c e}+1}=G_{0}=G_{N_{i c e}}=M_{N_{i c e}+1}=0$, and $H=H e\left(T_{f}-T\right)$ is the Heaviside step function, which distinguishes between supercooled and superheated plume states. Using (2.14), (2.15) also implicitly defines $w_{i}^{\prime}$. The terms $M_{i}, G_{i}$ and $N_{i}$ all have the same sign as the rate of change of $C_{i}$, so both $M_{i}$ and $G_{i}$ are positive during frazil formation. The formulation of each type of interaction term is now discussed individually.

\subsubsection{Growth}

The heat flux from a growing frazil crystal is given by

$$
q=\rho_{0} c_{0} N u K_{T} \frac{T_{f}-T}{r_{i}} 2 \pi r_{i} t_{i},
$$

where $N u=1$ is the Nusselt number (SJ), $K_{T}=1.4 \times 10^{-7} \mathrm{~m}^{2} \mathrm{~s}^{-1}$ is the molecular thermal diffusivity, the disk radius is used as the appropriate length scale for calculating the temperature gradient (Hammar \& Shen 1995) and $2 \pi r_{i} t_{i}$ is the surface area of the disk edge. Growth of frazil crystals is assumed to occur only at the disk edges because experiments have shown that the growth rate in the direction of the ice crystal $a$-axis is 1-2 orders of magnitude larger than the growth rate in the 
$c$-axis direction (Daly 1994b); the growth in the $a$-axis direction is limited primarily by the diffusion of latent heat or salt while growth of $c$-axis faces is limited by the attachment rate of water molecules to the ice surface.

Since salt diffuses more slowly than heat, salt rejection or the release of meltwater could in principle limit the rate of freezing or melting at a frazil crystal surface because increases in salinity decrease the freezing temperature of seawater (JB). Following SJ, whose conclusions were based on the calculations including the effect of salinity of Holland \& Jenkins (1999), we take the melting and freezing rates to be linear functions of $T-T_{f}$, where $T_{f}$ is evaluated using the bulk salinity of the plume. Therefore, we investigate the effect of a solutal boundary layer by decreasing $N u$ in a sensitivity study.

Under the assumption that the growth of frazil in turbulent seawater is controlled by the heat flux rather than salinity, the conversion of (2.16) to an ice production rate yields

$$
G_{i}=\frac{c_{0} N u K_{T}}{\mathscr{L}}\left(T_{f}-T\right) \frac{2}{r_{i}^{2}} C_{i}
$$

because the number of frazil crystals in a size class per unit volume, $n_{i}$, is related to volume concentration by $C_{i}=\pi r_{i}^{2} t_{i} n_{i}$.

\subsubsection{Melting}

Melting of frazil crystals is formulated in the same way as growth, but in this case there is no preference at the molecular level for phase change over any particular part of the ice crystal. Therefore, (2.16) is reformulated using the entire surface area of the crystal, and the resulting melt rate becomes

$$
M_{i}=\frac{c_{0} N u K_{T}}{\mathscr{L}}\left(T_{f}-T\right) \frac{2}{r_{i}}\left(\frac{1}{r_{i}}+\frac{1}{t_{i}}\right) C_{i} .
$$

\subsubsection{Secondary nucleation}

Secondary nucleation is the process whereby new frazil crystal nuclei are detached from 'parent' crystals. It has been suggested that this occurs through collisions between parent crystals and hard surfaces (including other crystals) and as a result of fluid shear (Daly 1994b). In this study the collision-based formulation of Svensson \& Omstedt (1994) is adopted, whereby a proportion of the ice crystals in each size class are converted to 'nuclei' (crystals in the smallest class) according to the frequency of crystal collision. SJ assumed that secondary nucleation only occurs in supercooled waters, since otherwise the new nuclei will soon melt away, but in this study secondary nucleation is activated all of the time because the breakup of larger crystals on collision still takes place in superheated conditions.

The volume swept by a crystal rising relative to the fluid during time $\Delta t$ is

$$
\Delta V=W_{i} \pi r_{i}^{e^{2}} \Delta t
$$

where $W_{i}$ represents the crystal velocity along a path which incorporates both rising and turbulent motions:

$$
W_{i}^{2}=\frac{4 \epsilon}{15 v_{0}} r_{i}^{e^{2}}+w_{i}^{2}
$$

In these expressions, $r_{i}^{e}$ is the effective radius of the rising crystal, which is equal to the radius of a sphere with the same volume as a disk of radius $r_{i}$. This quantity is used to approximate the effects of the frazil disk's varying orientation relative 
to its path as it rises. $\epsilon=7.4 \times 10^{-6} \mathrm{~W} \mathrm{~kg}^{-1}$ is the turbulent dissipation rate and $v_{0}=1.95 \times 10^{-6} \mathrm{~m}^{2} \mathrm{~s}^{-1}$ is the molecular viscosity of seawater.

The rate of secondary nucleation transfer from larger-crystal classes to class 1 (the smallest class) is proportional to the number of crystal collisions in the volume swept out in unit time:

$$
\begin{aligned}
N_{1} & =\sum_{i=2}^{N_{i c e}} \pi \tilde{n} \frac{W_{i}}{r_{i}^{e}} r_{1}^{e^{3}} C_{i}, \\
N_{i \neq 1} & =-\pi \tilde{n} \frac{W_{i}}{r_{i}^{e}} r_{1}^{e^{3}} C_{i},
\end{aligned}
$$

where $\tilde{n}$ is the average number of ice crystals of all sizes per unit volume, which is evaluated as part of the solution procedure. The model calibration of SJ is followed in limiting the efficiency of secondary nucleation by imposing $\tilde{n}_{\max }=10^{3}$ as a maximum value for $\tilde{n}$.

\subsection{Frazil precipitation}

The precipitation of buoyant frazil crystals out of a water column has previously been modelled as the rising flux through an open sea surface (Svensson \& Omstedt 1998) and as a parameterization of crystal settling onto an ice shelf (JB, SJ). The former is not justifiable for a fluid moving under surface cover and the latter is applicable only in a model in which the flow properties are averaged in the direction perpendicular to the solid boundary. In this section, these two approaches are combined to provide a model of frazil deposition that is suitable for general application to any water column beneath a no-slip boundary.

Before proceeding with the formulation, it is useful to review briefly the physics of turbulent boundary layers and their effect upon particle deposition. We generalize this discussion by defining a dimensionless distance from the wall, $z^{+}=u_{*} \hat{z} / v$, where $u_{*}$ is the friction velocity, $\hat{z}$ is the dimensional wall-normal coordinate (increasing away from the wall) and $v$ is the molecular viscosity. In this study a quadratic drag law is adopted such that $u_{*}^{2}=C_{d} U^{2}$, where $C_{d}=1.5 \times 10^{-3}$ (Holland \& Jenkins 1999) and $U$ is the plume speed parallel to the shelf, averaged in the shelf-normal direction over the whole dynamic boundary layer.

Adjacent to the no-slip boundary, there is a thin sublayer $\left(z^{+} \lesssim 7\right)$ where viscous stresses dominate, although the flow there may not be laminar (Cantwell 1981). Outside this viscous sublayer $\left(7 \lesssim z^{+} \lesssim 40\right)$, there is a 'buffer layer' in which turbulent stresses grow in importance and both viscous and turbulent stresses govern the flow. Farther out from the wall $\left(40 \lesssim z^{+} \lesssim 500\right)$, turbulent stresses are dominant and the velocity parallel to the wall can be described by the well-known logarithmic profile of von Kármán (1930).

In a parameterization of sedimentation from deep-ocean gravity currents, McCave \& Swift (1976) assume that the net flux of particles into the viscous sublayer is deposited. The settling of sediments into the sublayer region is regulated by turbulent structures in the buffer and logarithmic layers, with recent studies suggesting that quasi-streamwise vortices may be responsible for 'sweeps' and 'ejections' of sedimentladen fluid into and out of the viscous sublayer, respectively, phenomena collectively known as 'bursting' (Robinson 1991; Marchioli \& Soldati 2002). Sedimentation under buoyancy is reduced as bursting becomes more vigorous, because it is assumed that sweeps transport in lower concentrations of sediment than ejections carry out. 


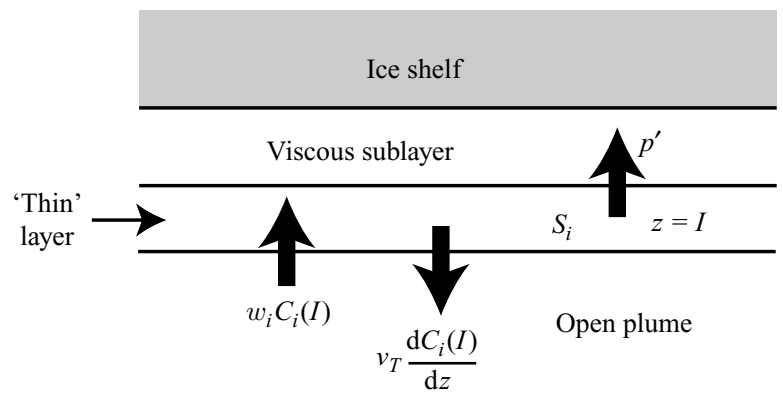

FiguRE 2. Schematic diagram of the frazil processes acting at the top of the domain. The balance of processes in the 'thin' layer gives the upper boundary condition for our frazil model; the viscous sublayer is excluded from the area in which calculations are performed.

Assuming that all net frazil transport into the sublayer is precipitated, the top of the active computational domain is defined to be a 'thin' layer $(z=I)$ situated at the base of the viscous sublayer, i.e. at $z^{+}=7$ (figure 2). Considering a vertical balance of frazil processes in the thin layer, we arrive at

$$
\frac{\partial C_{i}(I)}{\partial t}=w_{i} C_{i}(I)-v_{T} \frac{\partial C_{i}(I)}{\partial z}+S_{i}+p_{i}^{\prime},
$$

where the first three terms on the right-hand side represent rising into the thin layer, downwards diffusion out of it, and in situ transfer between size classes, while $p_{i}^{\prime}$ is the actual upwards precipitation rate of frazil in the $i$ th size class into the sublayer, i.e. out of the domain (see figure 2). $p_{i}^{\prime}$ is expressed as a thickness of ice per unit time and is defined to be negative when frazil is precipitated onto the ice shelf. Throughout this precipitation formulation, we neglect the tiny slope of the ice shelf base for convenience.

JB adapted the parameterization of McCave \& Swift (1976) to the case of frazil deposition from a turbulent ISW plume, using

$$
p_{i T}^{\prime}=-w_{i} C_{i}(I)\left(1-\frac{U^{2}+U_{T}^{2}}{U_{C i}^{2}}\right) H e\left(1-\frac{U^{2}+U_{T}^{2}}{U_{C i}^{2}}\right),
$$

where $U_{T}$ is a root-mean-square tidal velocity and $U_{C i}$ is a critical deposition velocity for each crystal size class, above which precipitation cannot occur. $U_{C i}$ is calculated from the assumption that frazil deposition is suppressed when the fluid stress could theoretically erode particles from the boundary. The step function prevents any erosion from actually taking place, since this formulation is inappropriate for such processes and too little is known about frazil crystal resuspension. According to the theory of JB, the threshold flow rate, which is calculated from the Shields criterion and our quadratic drag law, is

$$
U_{C i}^{2}=\frac{0.05\left(\rho_{0}-\rho_{I}\right) g 2 r_{i}^{e}}{\rho_{0} C_{d}} .
$$

An important weakness of this approach is that it is only valid for frazil volume concentrations of $C<10^{-3}$ (McCave \& Swift 1976). At higher concentrations, frazil ice may suppress the bursting enough to increase precipitation by increasing the viscosity of the mixture and/or by stabilizing the boundary layer. In order to set the correct precipitation rate, we require some way of quantifying the level of turbulence near the viscous sublayer. 
For the purpose of this study, it is useful to define a 'bursting layer', $0<z^{+}<70$, which is approximately the domain of the coherent vortices thought to be responsible for bursting (Jeong et al. 1997; Marchioli \& Soldati 2002). The relative importance of shear production to stability suppression of turbulence in this layer may be quantified through the gradient Richardson number:

$$
R i=\frac{-\frac{g}{\rho_{m}} \frac{\partial \rho_{m}}{\partial z}}{(\partial u / \partial z)^{2}}
$$

(e.g. Armenio \& Sarkar 2002; Tritton 1994).

The definition of $R i$ is now modified to provide a single dimensionless quantity that represents the effects of frazil-seawater mixture viscosity, shear and stability on turbulence. This quantity is then evaluated in the ecntre of the bursting layer $\left(z^{+}=35\right)$ to assess the viability of the vortices thought to be responsible for bursting (Marchioli \& Soldati 2002). In order to assess the viscous effects of increased frazil ice concentrations in the bursting layer, it is assumed that the shear stress exerted there by a steady externally driven flow is unchanged by an increase in the fluid viscosity:

$$
\tau_{0}=v_{0}\left(\frac{\partial u}{\partial z}\right)_{r e f}=v(C) \frac{\partial u}{\partial z} .
$$

This is equivalent to assuming that a change in molecular viscosity in the bursting layer alters only the velocity profile and therefore the shear at a given point. Combining (2.26) and (2.27), the modified Richardson number is

$$
R i=-\frac{g \nu(C)^{2}}{\rho_{m} v_{0}^{2}} \frac{\partial \rho_{m}}{\partial z}\left(\frac{\partial u}{\partial z}\right)_{r e f}^{-2} .
$$

In this study, the reference velocity gradient is calculated by employing the velocity profile predicted in the vicinity of $z^{+}=35$ by the law of the wall with the depth-mean velocity $U$, i.e. $(\partial u / \partial z)_{r e f}=C_{d} U^{2} /\left(35 v_{0} \kappa\right)$, where $\kappa=0.41$ is von Kármán's constant.

Unfortunately, the effect on mixture viscosity of increasing frazil concentrations is rather poorly understood. Newyear \& Martin (1999) matched results from a two-layer wave model (with a viscous frazil-seawater mixture overlying pure seawater) to an experimental investigation of wave damping by a layer of suspended frazil, finding that a model frazil mixture viscosity of approximately $v=0.02 \mathrm{~m}^{2} \mathrm{~s}^{-1}$ gave the best fit to the data at frazil concentrations of $C=0.47$. This appears to be the only time the molecular viscosity of a mixture of frazil and water has been estimated, so $v$ is increased linearly from the pure-water value $v_{0}$ at $C=0$ to the value found by Newyear \& Martin (1999).

The precipitation rate switches from turbulence-impeded precipitation $p_{i T}^{\prime}$ for $R i$ less than a critical value to full precipitation of all increases in frazil concentration in the thin layer when bursting is suppressed, so that

$$
\frac{\partial C(I)}{\partial t}=0
$$

in the laminar case and the precipitation rate is

$$
p_{i L}^{\prime}=\left(-w_{i} C_{i}(I)+v_{T} \frac{\partial C_{i}(I)}{\partial z}-S_{i}\right) H e\left(-w_{i} C_{i}(I)+v_{T} \frac{\partial C_{i}(I)}{\partial z}-S_{i}\right) .
$$

(As with $p_{i T}^{\prime}$, a step function is used to ensure that $p_{i L}^{\prime} \geqslant 0$ so that ice can never be eroded from the surface boundary.) 
The transition between the two precipitation rates is smoothed using an error function, yielding a final precipitation expression of

$$
p_{i}^{\prime}=p_{i T}^{\prime}+\frac{p_{i L}^{\prime}-p_{i T}^{\prime}}{2}\left\{1+\operatorname{erf}\left[d\left(R i-R i_{C}\right)\right]\right\},
$$

where $R i_{C}=0.25$ and $d=8$ are chosen so that $p_{i}^{\prime} \approx p_{i T}^{\prime}$ for $R i<0$ and $p_{i}^{\prime} \approx p_{i L}^{\prime}$ for $R i>0.5$ (Tritton 1994).

\section{Application to a well-mixed domain}

\subsection{Model description}

To examine the basic behaviour of the frazil dynamics model in the absence of precipitation, it was initially applied to the case of a 'well-mixed' supercooled domain in which there is no spatial variation in any modelled quantity. The governing equations (2.7) and (2.13) therefore become

$$
\frac{\partial C_{i}}{\partial t}=S_{i}
$$

and

$$
\frac{\partial T}{\partial t}=w^{\prime}\left(T_{f}-T-\frac{\mathscr{L}}{c_{0}}\right) .
$$

In the reference simulation presented here, $N_{i c e}=10$ size classes were used with radii of $\boldsymbol{r}=(0.01,0.05,0.15,0.3,0.4,0.5,0.6,0.8,1,2) \mathrm{mm}$, encompassing the significant range of frazil sizes observed in experiments and simulations to date (SJ). A fixed salinity representative of an ISW plume was used, taken to be $S=34.5$ psu according to Lane-Serff (1995). The initial frazil concentration was chosen to be $C_{i n}=4 \times 10^{-8}$ divided evenly between the size classes (SJ). To complete this simple scenario, a small initial supercooling of $\theta_{\text {in }}=10^{-4}{ }^{\circ} \mathrm{C}$ was imposed and the behaviour of the model was then observed as frazil ice formed to quench the supercooling and achieve steady thermal equlibrium.

In previous multiple-size-class studies of frazil dynamics, little reference has been made to the dependence of model results on the number of size classes into which the frazil population is divided. In this paper, the sensitivity of the reference simulation results to a variation in the number of frazil size classes is tested.

\subsection{Results}

\subsubsection{Basic results}

In this section, the results of the well-mixed box simulation described above are scrutinized, in which an initially uniform frazil distribution is allowed to evolve in response to a supercooling of $10^{-4}{ }^{\circ} \mathrm{C}$. As illustrated in figure 3 , the initial response of the model is to transfer frazil away from the smallest size class because growth of crystals in class 1 transfers them to class 2 , reducing $C_{1}$ if secondary nucleation is not rapid enough to replace the lost ice volume. With uniform initial conditions, ice concentrations in the other classes always initially increase because growth of frazil in class $i$ (which reduces $C_{i}$ by transferring crystals to class $i+1$ ) is always outstripped by growth in the class below $(i-1)$. A shortage of class 1 crystals eventually decreases the transfer into class 2 by growth, so that $C_{2}$ stops increasing so rapidly and $C_{3}$ becomes the dominant size class.

After approximately two days, the latent heat released from the growth of ice crystals quenches the initial supercooling entirely and growth ceases; this is defined 


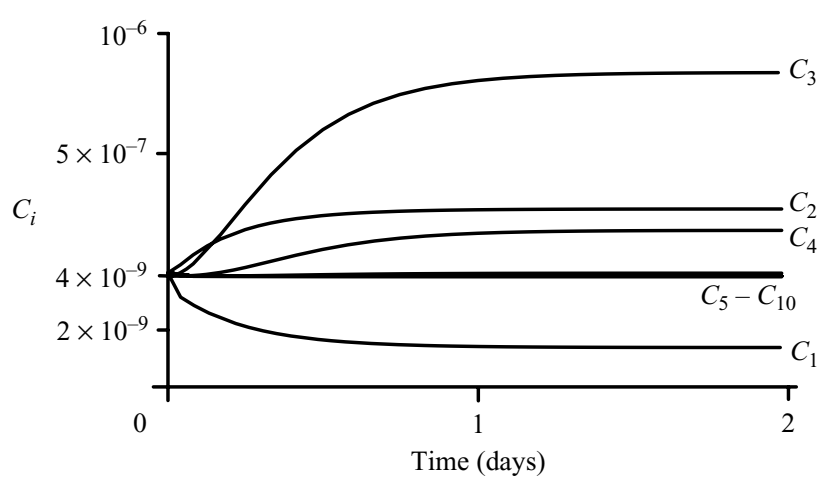

FIGURE 3. Evolution of the volume concentration in each frazil size class in the reference well-mixed simulation, which has an initial supercooling of $\theta_{\text {in }}=10^{-4}{ }^{\circ} \mathrm{C}$. Note the variable scale of the ordinate.

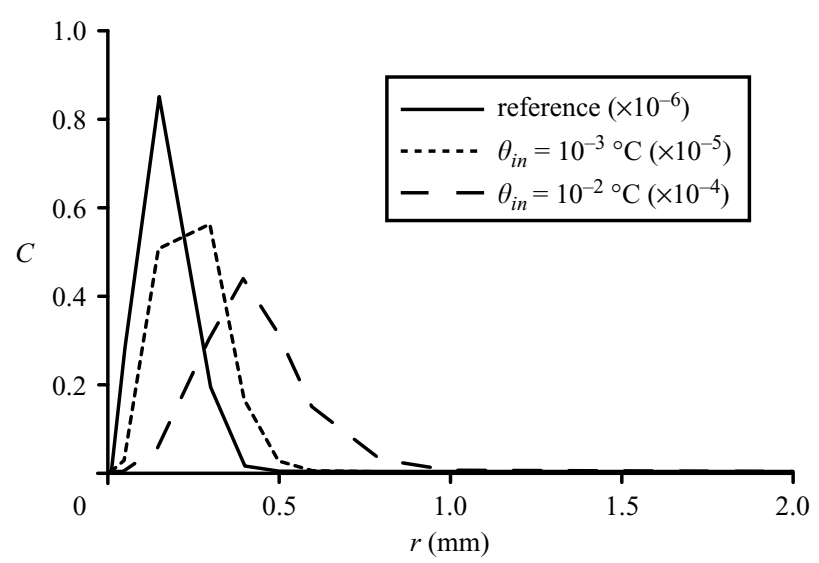

FIGURE 4. Frazil size distribution in the quasi-steady state of the well-mixed case for a range of initial supercoolings. The order of magnitude of the frazil concentration is different for each curve, as the larger initial supercoolings require more ice formation to achieve thermal equilibrium.

to be the quasi-steady state of the well-mixed simulations. The size distribution of frazil ice in the quasi-steady state of this reference simulation is shown in figure 4 . The frazil size distribution has a well-defined peak towards the smaller end of the crystal size spectrum, with a significant radius (modal size class) of $r_{s}=0.15 \mathrm{~mm}$.

When the quasi-steady state is achieved, the only frazil interaction terms which remain are those associated with secondary nucleation. This process subsequently transfers all ice back to the smallest frazil size class, where it remains because there is no further growth owing to the absence of supercooling. With the model parameters adopted here, this genuine steady state takes an extremely long time to achieve, implying that the growth and secondary nucleation processes take place on vastly different time scales. Indeed, experiments show that these results are altered only slightly by the exclusion of secondary nucelation terms. However, secondary nucleation may still be important in other simulations with longer growth periods or different parameter choices owing to the disproportionate effect of adding a few crystals to the smallest size class when larger crystal sizes are prevalent. 
The initial supercooling of $\theta_{i n}=10^{-4}{ }^{\circ} \mathrm{C}$ used in the reference simulation is a mean value from the results of SJ. However, it is possible that much larger supercoolings may arise; Nicholls, Makinson \& Østerhus (2004) recorded a supercooling of $0.035^{\circ} \mathrm{C}$ beneath FRIS and Nicholls \& Jenkins (1993) suggest that supercoolings of up to $0.05^{\circ} \mathrm{C}$ could occur there. Therefore, further test simulations were performed in which $\theta_{\text {in }}$ is increased to $10^{-3}{ }^{\circ} \mathrm{C}$ and $10^{-2}{ }^{\circ} \mathrm{C}$.

While the qualitative behaviour of all of these simulations is the same, increasing the initial supercooling accelerates the growth of frazil ice considerably. The quasi-steady state is reached by the $\theta_{\text {in }}=10^{-3}{ }^{\circ} \mathrm{C}$ and $\theta_{i n}=10^{-2}{ }^{\circ} \mathrm{C}$ simulations in approximately one day and 12 hours, respectively, even though the frazil volume change from initial conditions required to produce these quasi-steady states rises in line with the increase in $\theta_{i n}$. Analysis of the growth term (2.17) reveals that it is the dependence of growth rate $G_{i}$ on both $C_{i}$ and $T_{f}-T$ that provides the nonlinearity required for the simulations with larger initial supercoolings to reach their target volume in a significantly shorter time.

The significant radius in the quasi-steady state is increased by a higher $\theta_{\text {in }}$ (figure 4) because more frazil growth must take place to quench the supercooling. As before, the initial frazil volume in class 1 is transferred to higher classes, initiating a reduction of $G_{1}$ and subsequent decrease in $C_{2}$, but this effect now cascades up the size classes (reducing $G_{2}$ and thus $C_{3}$ and so on) because the quasi-steady state is not yet attained. The net result is to shift more frazil to larger radii and thus increase $r_{s}$ and spread the frazil distribution over a wider range (figure 4).

\subsubsection{Response to variations in $N_{\text {ice }}$}

In this section, the robustness of these results to a change in the number of size classes $N_{\text {ice }}$ is examined, since any result which is found to be dependent upon $N_{\text {ice }}$ should be regarded as potentially suspect. SJ also performed such a test, finding that the total ice production and significant radius were the same, while the amount of ice resisting precipitation changed because crystals reached the larger classes (with greater rise velocities) at a different rate. By performing model simulations with uniformly distributed initial conditions and $N_{\text {ice }}$ varying from 3 to 200, it is classified here exactly which model features are sensitive to variation in $N_{\text {ice }}$.

The character of frazil growth in a 200-class simulation is qualitatively similar to that of the 10-class simulation: initial supercooling causes growth in all classes apart from the smallest, and limitation of the small crystal supply then causes a peak in concentration to form. The significant radius in the quasi-steady state varies slightly between simulations, but stays between $0.1 \mathrm{~mm}$ and $0.15 \mathrm{~mm}, 2.5 \%$ of the total range of radii, regardless of the number of frazil classes. The total ice volume produced is the same in all simulations.

The concentration of frazil in each size class decreases as $N_{i c e} \rightarrow \infty$ (to preserve the correct prediction of total ice volume), therefore frazil concentrations in classes from a high- $N_{\text {ice }}$ simulation are grouped into 'bins' for comparison with frazil concentrations from a lower- $N_{\text {ice }}$ simulation. The agreement between simulations that use different numbers of size classes should improve as the number of size classes in each increases. Comparing quasi-steady state $N_{i c e}=10$ simulation results with $N_{i c e}=20$ simulation results grouped into 10 bins (figure $5 a$ ), it is clear that increasing the number of size classes does affect the results slightly, whereas comparing results from a $N_{i c e}=100$ simulation to results of a 200-class simulation grouped into 100 bins (figure $5 b$ ), it is evident that these differences disappear as $N_{i c e}$ increases and the model results converge to a consistent solution. 

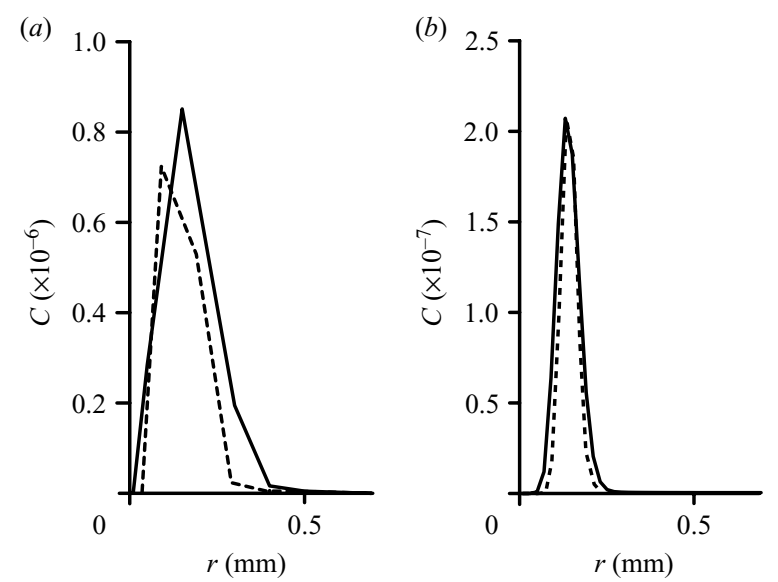

FIGURE 5. Demonstration of the quasi-steady state agreement between mixed-box frazil simulations in which the number of size classes is varied: $(a)$ results from a $N_{i c e}=10$ simulation (solid) and a $N_{i c e}=20$ simulation with frazil concentrations grouped into 10 'bins' (dotted), (b) results from a $N_{i c e}=100$ simulation (solid) and a $N_{\text {ice }}=200$ simulation grouped into 100 'bins' (dotted).

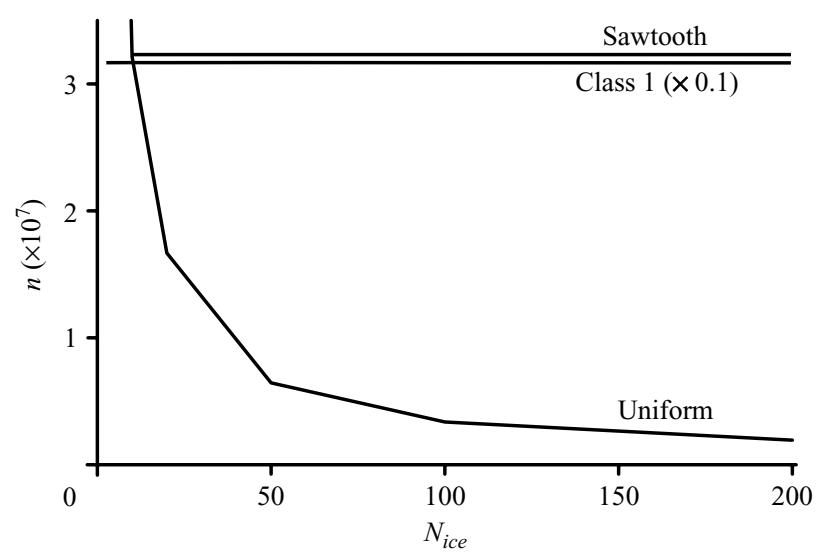

FIGURE 6. Dependence of the number of crystals in the quasi-steady state (after $10^{7} \mathrm{~s}$ ) on the number of size classes in each simulation. The three curves show three groups of simulations in which the same initial ice volume is spread over the size classes in three different ways. The 'uniform' initial conditions initially have $C_{i n} / N_{\text {ice }}$ in each size class for all simulations, the 'class 1' conditions (multiply scale by 10 ) initially have all $C_{i n}$ in class 1 and the 'sawtooth' conditions have initial frazil concentrations of $C_{i n} / 10$ in each size class which has a radius matching that of the reference $N_{\text {ice }}=10$ simulation.

If initial conditions are used in which $C_{i n}$ is divided between a range of size classes, increasing $N_{\text {ice }}$ necessarily changes the number of frazil crystals in the domain because the same initial ice volume is spread over classes with different radii. It also therefore changes the total frazil growth rate per unit supercooling, since growth is dependent upon crystal radius. These changes imply that, with such initial conditions, increasing $N_{\text {ice }}$ affects both the final number of frazil crystals and the time it takes to achieve the quasi-steady state (figure 6).

Using initial conditions in which $C_{i n}$ is divided over a range of radii implies that increasing $N_{i c e}$ actually changes the initial frazil size distribution because the crystals 
are at different radii corresponding to the new size classes. Results from a range of simulations in which all initial frazil is in class 1 (and $r_{1}$ is fixed) show no significant variation in any quantity as $N_{\text {ice }}$ varies (figure 6), supporting the hypothesis that dependence upon $N_{i c e}$ is a feature of the initial conditions. Similar $N_{i c e}$-independence is found when 'sawtooth' initial conditions are assigned in the test cases: $C_{i n} / 10$ is assigned to each class with a radius matching that of a class from the $N_{\text {ice }}=10$ simulation, and all other classes are initially set empty. It may seem that the $N_{\text {ice }}$ dependence is therefore a consequence of our testing strategy, but since the original 10 classes are arbitrarily chosen this study actually shows that any kind of distributed initial conditions will produce size-class dependence in the number of frazil crystals and, consequently, the volume growth rate.

\section{Application to an ISW plume}

\subsection{Model description}

The processes leading to vertical variation in frazil populations are illustrated by applying the frazil model to a one-dimensional vertical section through an ISW plume from the study of SJ. To customize the model to this case, a scaling analysis is undertaken to determine the relevant terms of the two governing equations.

First, the frazil crystal mass balance in the $i$ th class (2.7) in the vertical and along-plume directions is

$$
\frac{\partial C_{i}}{\partial t}+u \frac{\partial C_{i}}{\partial x}+\left(w+w_{i}\right) \frac{\partial C_{i}}{\partial z}=\frac{\partial}{\partial x}\left(v_{T} \frac{\partial C_{i}}{\partial x}\right)+\frac{\partial}{\partial z}\left(v_{T} \frac{\partial C_{i}}{\partial z}\right)+S_{i},
$$

where $x$ is taken to be parallel to the plume path and $z$ is vertical depth. The frazil rising velocity scale $\bar{w}_{i}=3 \times 10^{-3} \mathrm{~m} \mathrm{~s}^{-1}$ is calculated for frazil crystals with $r_{i}=1 \mathrm{~mm}$ and the plume velocity scales $\bar{u}=5.5 \times 10^{-2} \mathrm{~m} \mathrm{~s}^{-1}$ and $\bar{w}=1.2 \times 10^{-4} \mathrm{~m} \mathrm{~s}^{-1}$ are taken from the mean flow in the frazil deposition zone of the Foundation Ice Stream case of SJ (see below). This predicted flow rate is in good agreement with the more sophisticated modelling of Jenkins \& Holland $(2002 a, b)$ and the calculated mean Filchner Depression circulation rate of Nicholls \& Østerhus (2004), which is probably the closest observation to an ISW plume flow rate in the literature. $v_{T}$ is set to $10^{-3} \mathrm{~m}^{2} \mathrm{~s}^{-1}$ in these analyses according to Gerdes et al. (1999). $\bar{x}$ and $\bar{z}$ are related by the assumption that they are scales over which supercooling increases such that an $O$ (1) change in $C_{i}$ occurs, implying that $\bar{z}=s_{\theta} \bar{x}$, where $s_{\theta}=1 / 450$ is the slope of the ice shelf base. $\bar{z}$ is determined by assuming a balance between rising and diffusion, yielding $\bar{z}=0.33 \mathrm{~m}$ with the values of $w_{i}$ and $v_{T}$ adopted here, and the value of $\bar{x}=150 \mathrm{~m}$ follows. $\bar{z}$ can be interpreted as the distance from the ice shelf at which this balance holds in steady state.

Using these characteristic scales, the dimensionless form of (4.1) becomes

$$
\begin{gathered}
\frac{1}{\bar{t}} \frac{\partial C_{i}^{*}}{\partial t^{*}}+3.7 \times 10^{-4}\left(u^{*} \frac{\partial C_{i}^{*}}{\partial x^{*}}\right)+3.7 \times 10^{-4}\left(w^{*} \frac{\partial C_{i}^{*}}{\partial z^{*}}\right)+9 \times 10^{-3}\left(w_{i}^{*} \frac{\partial C_{i}^{*}}{\partial z^{*}}\right) \\
=4.4 \times 10^{-8}\left(\frac{\partial^{2} C_{i}^{*}}{\partial x^{* 2}}\right)+9 \times 10^{-3}\left(\frac{\partial^{2} C_{i}^{*}}{\partial z^{* 2}}\right)+\frac{\bar{S}_{i}}{\bar{C}_{i}} S_{i}^{*} .
\end{gathered}
$$

This shows that frazil rising and vertical diffusion of frazil (the fourth and sixth terms) are larger than the advection and horizontal diffusion terms (second, third and fifth terms). For computational simplicity, the advection and horizontal diffusion terms are therefore neglected. Frazil interaction terms are left undetermined because 
many case-specific assumptions are required to find their magnitude and they are the focus of the present study.

It should be noted that, for smaller crystals, $\bar{z}$ can be larger as a result of the lower velocity used in the rising-diffusion balance. Calculations show that for crystals with $r_{i} \lesssim 0.2 \mathrm{~mm}$, advection terms become comparable to rising and diffusion. This study is presented as a simple example of vertical variation in frazil dynamics; more complex, multidimensional hydrodynamics (required if horizontal advection terms become important) will be the subject of future work. Since we are primarily concerned with frazil deposition in this study, a balance based on larger, more buoyant crystals is the most appropriate choice here.

The temperature transport equation corresponding to (4.1) is

$$
\frac{\partial T}{\partial t}+u \frac{\partial T}{\partial x}+w \frac{\partial T}{\partial z}=\frac{\partial}{\partial x}\left(v_{T} \frac{\partial T}{\partial x}\right)+\frac{\partial}{\partial z}\left(v_{T} \frac{\partial T}{\partial z}\right)+w^{\prime}\left(T_{f}-T-\frac{\mathscr{L}}{c_{0}}\right) .
$$

The same plume velocity and length scales are used as before, giving the magnitudes quoted in (4.2) for diffusion and advection and therefore allowing us to neglect the second, third and fourth terms of (4.3). We retain the final heat source term as previously discussed.

Therefore, the final governing equations for this model application become

$$
\frac{\partial C_{i}}{\partial t}=\frac{\partial}{\partial z}\left(v_{T} \frac{\partial C_{i}}{\partial z}\right)-w_{i} \frac{\partial C_{i}}{\partial z}+S_{i}
$$

and

$$
\frac{\partial T}{\partial t}=\frac{\partial}{\partial z}\left(v_{T} \frac{\partial T}{\partial z}\right)+w^{\prime}\left(T_{f}-T-\frac{\mathscr{L}}{c_{0}}\right) .
$$

Since frazil precipitation and depth-variation in ISW plumes are the main topics of interest in this study, the vertical plume model is sited in the Foundation Ice Stream section of SJ's results, $400 \mathrm{~km}$ from the grounding line and at a point at which the plume is neither supercooled nor superheated on depth-average. This area, immediately east of the northern tip of Henry Ice Rise, is intensively studied by SJ and also has a deep plume and some of the most active refreezing beneath FRIS (Joughin \& Padman 2003). The latter study evaluates the basal accumulation rate to be 3-4 $\mathrm{m}_{\text {year }}{ }^{-1}$ there whereas SJ predict a freezing and precipitation rate of $0.5-1 \mathrm{~m}$ year ${ }^{-1}$ in the vicinity of this location.

The modelled plume section was $60 \mathrm{~m}$ deep and laid between the ambient seawater and an ice shelf extending to $470 \mathrm{~m}$ beneath sea level. Neither the ice shelf nor ambient water were included in the computational domain. The same plume salinity and 10 size classes were used as in the well-mixed case described above. The depth-mean velocity parallel to the ice shelf was $U=0.055 \mathrm{~m} \mathrm{~s}^{-1}$ (SJ), the tidal r.m.s. velocity was $U_{T}=0.06 \mathrm{~m} \mathrm{~s}^{-1}(\mathrm{SJ})$ and the vertical eddy diffusivity was taken to be $v_{T}=10^{-3} \mathrm{~m}^{2} \mathrm{~s}^{-1}$ as before. The effect of the small slope in the ice shelf base is negligible. Since SJ predict zero depth-average supercooling at this location, a uniform initial temperature of $T_{i n}=\left.T_{f}\right|_{z=I / 2}$ was used, resulting in a plume with maximum supercooling at the top and maximum superheating at the bottom (both $\approx 0.02{ }^{\circ} \mathrm{C}$ ).

In the reference simulation, the initial population of frazil ice was chosen to be the small and uniform seeding distribution of SJ, as adopted in the well-mixed study. While clearly unrealistic for this late stage of the plume's development, these conditions produce an idealized one-dimensional study of the effects of depth-variation throughout all stages of a general ISW plume. As part of the sensitivity studies 

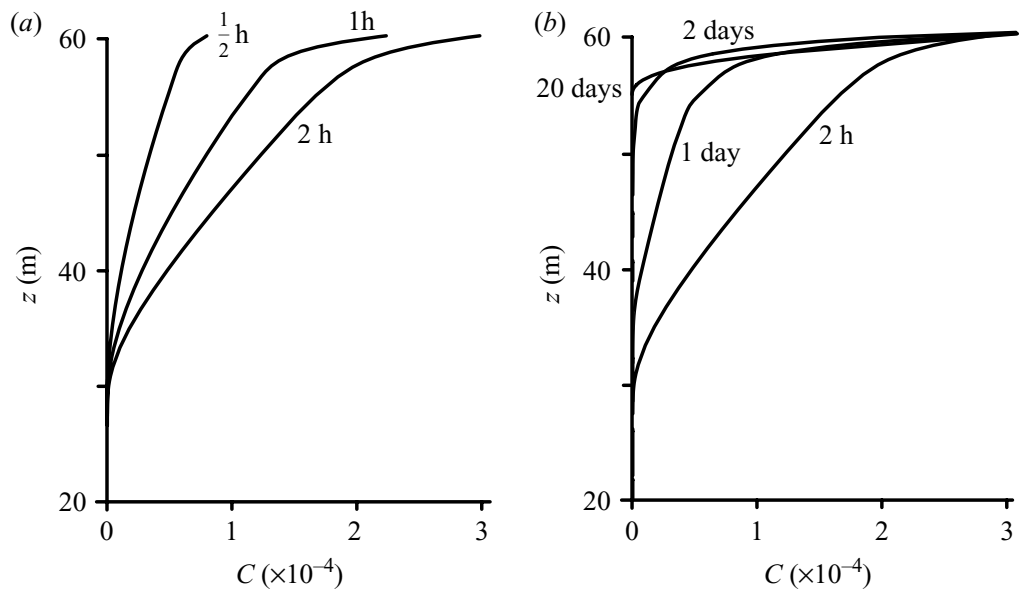

FiguRE 7. Total frazil concentration over the top $40 \mathrm{~m}$ of the plume for $(a)$ the first two hours and $(b)$ the first 20 days. The initial growth of frazil gives way to rising and precipitation until an approximate balance of transport terms in the frazil governing equation forms the quasi-steady state. Frazil growth is restricted to the upper half of the plume where supercooling is initially present.

performed on the results of this reference simulation, we also consider a case in which the initial frazil concentrations were taken to be the population predicted by SJ at this point in the plume's evolution.

Apart from frazil precipitation at the ice shelf base, boundary conditions of zero flux are set for all variables on all boundaries. Direct melting or freezing at the base of the ice shelf is neglected in this model, and there is no entrainment of frazil because the ambient waters are free of ice. The heat flux between the plume and ambient water is neglected because the effects of plume entrainment are already incorporated into the model via the adoption of plume depth and velocities from SJ. In addition, any attempt to introduce a further heat flux over the course of our simulations will result in an arbitrary modelling of the effects of horizontal advection, which have already been removed by the scaling analysis. Therefore the boundary conditions are

$$
\begin{aligned}
\frac{\partial T}{\partial z} & =0 \quad(z=0, I), \\
\frac{\partial C_{i}}{\partial z} & =0 \quad(z=0),
\end{aligned}
$$

and (2.23).

\subsection{Results}

\subsubsection{Reference simulation}

The findings presented in this section illustrate the growth and precipitation response of the frazil model to depth-dependent supercooling. This simulation uses the same uniform initial conditions as before, illustrating as simply as possible the frazil ice dynamics in this physical scenario. For the purpose of this discussion, the results of the reference simulation are arbitrarily divided into four periods: the initial growth phase; a transitional phase; a quasi-steady state; and the true steady state.

As shown in figure $7(a)$, the initial growth period (defined to be the first two hours of simulation) is dominated by the growth of frazil ice in the upper half of the domain 


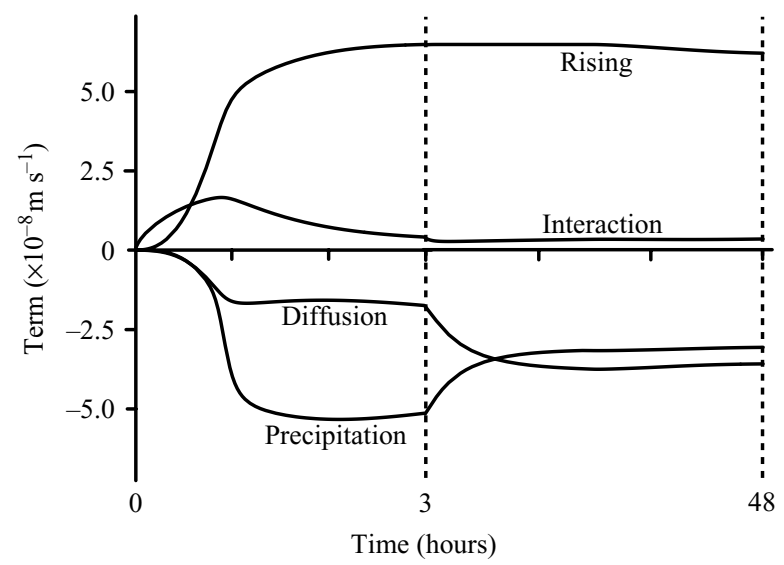

FiguRE 8 . Balance of terms in the frazil governing equation in the thin layer $(z=I)$ over the first two days of simulation. Note the different scales used in different sections of the abcissa. Initial frazil growth is overtaken by transport terms before precipitation switches to its laminar mode after approximately one hour and the quasi-steady balance forms after one day.

in response to the initial supercooling. This frazil forms a narrow layer immediately beneath the ice shelf, where the maximum supercooling is located and buoyant rising of crystals increases the in situ population. The ice formation releases latent heat that tends to quench the supercooling, although the entire upper half of the plume is still marginally supercooled after the first two hours of simulation. The initial ice volume is melted in the lower half of the plume, cooling it very slightly from its initially superheated state.

For the rest of the first two days of simulation there is a transition from this initial growth to a balanced state in which the majority of the plume is devoid of frazil; the end of this transitional phase marks the onset of the quasi-steady state (figure $7 b$ ). Throughout this period, frazil growth decreases and the importance of transport terms increases, as demonstrated by the relative magnitude of terms in the frazil governing equation in the thin layer at $z=I$ (see figure 8 and (2.23)). The total ice concentration and stability at the top of the plume both increase until $R i$ exceeds its critical value (after approximately one hour) and subsequently precipitation reverts to its full laminar mode, suppressing any further increase in ice concentration. Closer examination reveals that the early influence of increasing frazil concentrations upon viscosity (and thereby shear) is responsible for most of the rise in $R i$, but $R i$ actually takes the rest of the first day to attain a constant value as frazil rising continues to steepen the concentration gradient at the upper boundary and thus increase the stability there (figure $7 b$ ). During this time the frazil growth becomes almost completely suppressed as the supercooling diminishes.

The quasi-steady state, which persists from day two onwards, is a period in which the frazil population maintains a vertical equilibrium and virtually all of the domain is warmer than the local freezing temperature. With a progressively narrower area of supercooling remaining near the ice shelf (figure 9), a situation is reached where the downwards diffusion and constant precipitation of ice out of the domain balance the rising of frazil and a small ice growth in the very top of the plume (figure 10). Since $R i$ is constant by this stage, precipitation of frazil ice remains steady throughout this period. The heat released by the initial growth of frazil continues to diffuse 


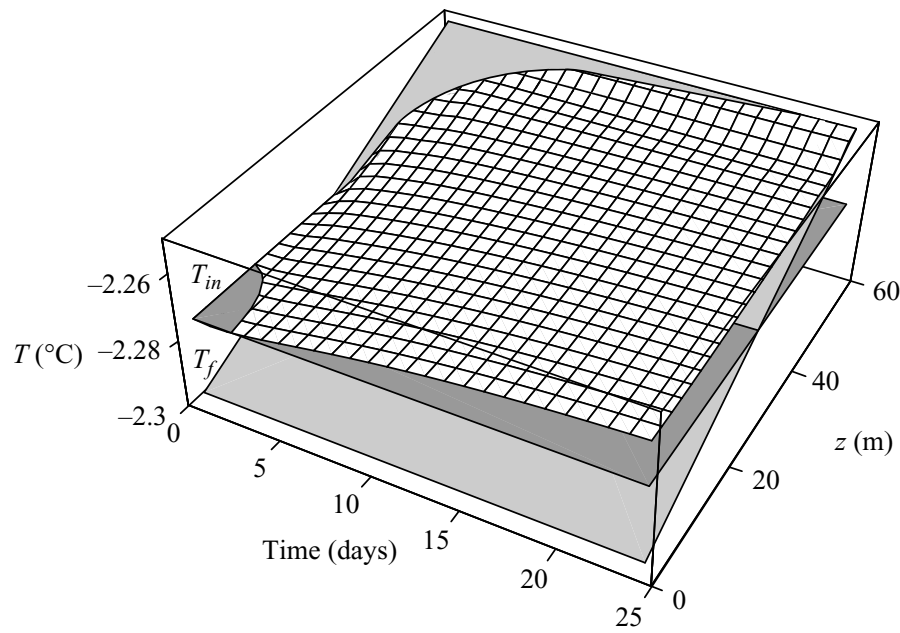

FiguRE 9. Plume temperature over the first 25 days of simulation, with surfaces corresponding to the initial and freezing temperatures also plotted. The entire top half of the plume is initially supercooled, but frazil formation subsequently confines the supercooling to an upper region that becomes progressively narrower until the whole plume is superheated.

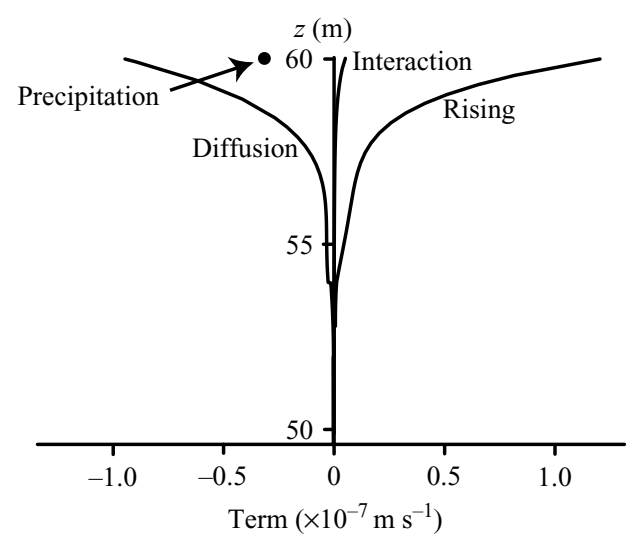

FIGURE 10. Vertical balance of terms in the frazil governing equation in the top $10 \mathrm{~m}$ of the plume after two days of simulation. This illustrates the balance referred to as the quasi-steady state, in which diffusion and precipitation offset rising and growth.

downwards and the supercooled region at the top of the plume slowly disappears owing to the small near-shelf frazil growth (figure 9).

The size distribution of frazil crystals throughout the top half of the domain initially evolves in the same way as observed in the well-mixed case, with the significant radius increasing over the first two hours as the overall population grows (figure 11). These crystals rise toward the ice shelf, so the local population decays when growth starts to recede, with significant radius $r_{s}$ decreasing in the process because the larger crystals rise preferentially. Conversely, at the very top of the plume this rising increases local frazil concentrations and the significant radius. $C(I)$ and $r_{s}(I)$ remain absolutely constant in the quasi-steady state, since the precipitation formulation for laminar conditions (2.30) ensures that the concentration in each size class at $z=I$ is fixed. 


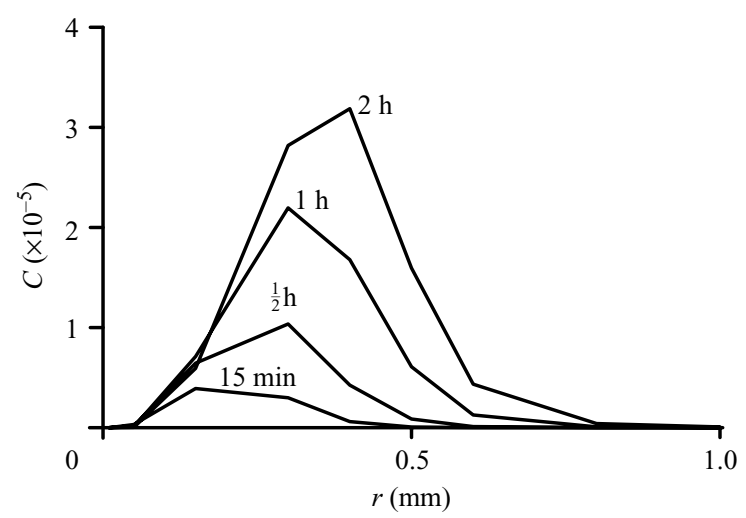

Figure 11. Distribution of frazil crystals at $z=45 \mathrm{~m}$ at various times during the first two hours of simulation. The significant radius and total frazil volume increase as the supercooling is taken up by frazil growth.

\begin{tabular}{lccc}
\multicolumn{1}{c}{ Simulation } & $r_{s}(I)(\mathrm{mm})$ & $C(I)$ & $p^{\prime}\left(\mathrm{m} \mathrm{year}^{-1}\right)$ \\
Reference & 0.5 & $3.06 \times 10^{-4}$ & -1.05 \\
$\nu_{T}=10^{-4} \mathrm{~m}^{2} \mathrm{~s}^{-1}$ & 0.4 & $2.59 \times 10^{-4}$ & -4.76 \\
$\nu_{T}=10^{-2} \mathrm{~m}^{2} \mathrm{~s}^{-1}$ & 0.6 & $1.95 \times 10^{-5}$ & -0.68 \\
Low speed & 0.5 & $2.18 \times 10^{-4}$ & -0.89 \\
High speed & 0.4 & $9.22 \times 10^{-4}$ & -110.16 \\
$C_{d}=1.5 \times 10^{-4}$ & 0.5 & $2.13 \times 10^{-4}$ & -0.88 \\
$C_{d}=1.5 \times 10^{-2}$ & 0.5 & $7.71 \times 10^{-4}$ & -91.03 \\
$N u=0.2$ & 0.4 & $2.68 \times 10^{-4}$ & -0.895 \\
SJ initial conditions & 0.5 & $4.98 \times 10^{-4}$ & -3.03
\end{tabular}

TABLE 1. The effect of varying selected model parameters. All quantities are evaluated after one day of simulation, when all simulations have achieved their quasi-steady state apart from the $v_{T}=10^{-2} \mathrm{~m}^{2} \mathrm{~s}^{-1}$ case, in which $R i$ never exceeds its critical value.

The final steady state occurs at a much later time (1-2 months) when the whole plume is warmed to the equilibrium freezing temperature evaluated at the base of the ice shelf. All supercooling is then eliminated from the domain and no frazil ice is present, so the vertically integrated temperature rise over the course of the simulation exactly matches the total latent heat release from all frazil which has formed and precipitated onto the ice shelf.

\subsubsection{Sensitivity studies}

The main focus of this section is the sensitivity of results to changes in the quantities directly related to precipitation and depth-variation. To consider the behaviour of our precipitation formulation over a range of possible ice shelf and plume characteristics, we vary $C_{d}, U$ and $U_{T}$, and to examine variations in depth-dependence, we consider changes in the constant value specified for the vertical diffusivity. In order to apply the model to the deposition phase of an ISW plume that is already laden with frazil crystals, as opposed to one in which growth has yet to occur, we study the effects of using initial conditions that match the frazil concentrations predicted by SJ at the chosen plume location. The variation of some important model features is summarized in table 1 . 
When $v_{T}$ is reduced by an order of magnitude, the model produces a similar frazil profile to that of the reference simulation. The quasi-steady state values of $C(I)$ and $r_{s}(I)$ are both lower than in the reference simulation because $R i$ exceeds its critical value sooner; the weakened diffusion allows frazil rising to induce a steeper concentration gradient (and hence higher stability) for a given value of $C(I)$. The quasi-steady precipitation rate, which is required to produce a balance of terms in the laminar thin layer, is increased significantly to compensate for the reduced diffusion.

In contrast, increasing $v_{T}$ by an order of magnitude produces a qualitative change in the model predictions. Flow in the thin layer never becomes laminar because the large concentration gradients required to stably stratify it are prevented by stronger turbulent diffusion and its suppression of crystal rising. Since the laminar precipitation formulation is never deployed, this simulation has no quasi-steady state and, after the familiar initial growth period, the frazil population quickly disappears as a result of the reduced growth rates, ongoing turbulent precipitation and stronger downwards diffusion of frazil.

The 'low speed' simulation is accomplished by setting $U=0.025 \mathrm{~m} \mathrm{~s}^{-1}$ and $U_{T}=0$, values which are much lower than predictions for the Foundation Ice Stream plume according to SJ. Results from this simulation are almost identical to those from a simulation with a low drag coefficient specified at the base of the ice shelf $\left(C_{d}=1.5 \times 10^{-4}\right)$. This implies that the influence of tides and turbulent precipitation is small in these simulations, since the appearance of $U$ and $U_{T}$ in (2.24) is the primary difference between varying $U$ and $C_{d}$. The main consequence of reducing these quantities is a reduction in the friction velocity, which widens the boundary layer and allows larger eddies to be involved in bursting. $R i$ is therefore evaluated further from the ice shelf (at a position of lower shear) and the flow in the thin layer becomes laminar at a smaller stabilizing density (concentration) gradient, reducing the value of $C(I)$ in the quasi-steady state. The prediction of less frazil precipitation in these simulations is a consequence of the lower $C(I)$, since this reduces the rising flux more than the diffusion and less precipitation is then required to balance the thin layer.

The opposite results are given by the 'high speed' $\left(U=0.2 \mathrm{~m} \mathrm{~s}^{-1}, U_{T}=0.05 \mathrm{~m} \mathrm{~s}^{-1}\right.$ according to $\mathrm{SJ})$ and high $\operatorname{drag}\left(C_{d}=1.5 \times 10^{-2}\right)$ simulations, which are also similar to each other. Increasing $u_{*}$ compresses the boundary layer so that larger concentration gradients are required to switch to laminar precipitation. This leads to much larger quasi-steady-state values for $C(I)$ and unrealistically large precipitation rates. Predictions of higher precipitation for faster plumes or a rougher boundary are clearly unphysical, since increased turbulence should suppress frazil precipitation, but it should be noted that the eddy diffusivity (which partially determines the precipitation rate) is held at its reference value in all of these tests, which is inconsistent with varying $U$ or $C_{d}$. This highlights the importance of using a realistic turbulent diffusivity (or, ideally, a higher-order turbulence closure) when using our precipitation formulation.

The possible influence of a solutal boundary layer on the melting and freezing rates at frazil crystal surfaces is tested by reducing $N u$ to 0.2 (following SJ). The effect of this change is to slow down the crystal interaction terms relative to the rising and diffusion terms. This results in a delay in the attainment of the quasi-steady state and a lower significant radius when it is reached. $C(I)$ is also slightly lower in the quasi-steady state because rising of frazil is of higher relative importance near the surface, producing a sharper concentration gradient there. However, in agreement with SJ, our model predicts that inclusion of the effect of a solutal boundary layer at the frazil crystal surfaces does not qualitatively affect frazil growth in ISW plumes. 
The simulation which starts from the initial conditions of SJ confirms that the reference simulation results are qualitatively representative of frazil ice populations during the deposition phase of an ISW plume. The main effect of adopting these alternative initial conditions is to increase the total initial ice concentration, leading to cooling of the plume at depth as a result of melting and a higher growth rate in the upper half of the plume. The quasi-steady state has a larger near-shelf frazil concentration owing to reduced stability in the early stages of the simulation and, as in other cases, this leads to a larger rising flux and increased precipitation. Since we have used initial conditions appropriate to a specific location in SJ's Foundation Ice Stream plume, our precipitation rate could be regarded as a modification to their results at this position. The depth-averaged model plume of SJ predicts along-shelf frazil dynamics, the direct freezing rate, and plume temperature and depth, while our model predicts the additional frazil growth and deposition which occurs if depthdependence is subsequently included. Although our quasi-steady precipitation rate applies for only 1-2 months, in reality there is a constant supply of supercooled water to this location and therefore it is appropriate to use the quasi-steady rate for the whole year. As a crude manner of validating our precipitation model, it should be noted that adding our quasi-steady precipitation rate of $3 \mathrm{~m} \mathrm{year}^{-1}$ to the ice accretion rate of SJ $\left(0.5-1 \mathrm{~m}\right.$ year $\left.{ }^{-1}\right)$ gives the local precipitation estimate of Joughin \& Padman (2003) (3-4 m year $\left.{ }^{-1}\right)$.

\section{Discussion}

In this paper, results are presented from a frazil ice dynamics model that incorporates a new formulation of the precipitation of buoyant frazil crystals into a turbulent boundary layer. This formulation is suitable for use in a multi-dimensional ISW plume model that incorporates frazil ice. The model is tested in two idealized domains: a 'well-mixed' case with no spatial variation or frazil precipitation and a one-dimensional plume cross-section with depth-dependent supercooling.

The study of the 'well-mixed' case showed that, as required, the most important results of total ice volume and significant radius are never sensitive to changes in the number of size classes $N_{i c e}$. Small discrepancies in results of the volume concentration between simulations with different numbers of size classes disappear as $N_{\text {ice }} \rightarrow \infty$ regardless of the initial conditions used; in any case the discrepancies between $N_{\text {ice }}=10$ and $N_{\text {ice }}=20$ simulations are so small that it can be argued that 10 classes are sufficient. A number of solution features, however, are sensitive to $N_{\text {ice }}$ variation. If initial conditions are used in which ice is distributed amongst several size classes, the model predictions of crystal number and the time taken to achieve the quasi-steady state can vary sharply with $N_{\text {ice }}$. This can have important consequences in studies predicting the location of frazil precipitation. In practice, these findings suggest that all initial frazil should be put into one size class (as in the study of Hammar \& Shen 1995) unless there is a good reason to do otherwise.

The reference model of a cross-section through an ISW plume shows that a considerable vertical variation can occur as a result of the depth-dependence of the freezing temperature. Any vertically uniform plume temperature less than the freezing temperature at the ice shelf base will produce a supercooling that decreases with depth, resulting in favourable conditions for frazil growth near the ice shelf, where populations are also enhanced by crystals rising from below under their own buoyancy. A water parcel of uniform temperature that is cooled relative to the local freezing point (e.g. owing to rising) will become supercooled at the top first (since the freezing 
temperature is higher there) and our simulations imply that the supercooling there will be quenched last. Only multi-dimensional modelling will reveal whether this is important in determining the dynamics of an ISW plume.

As frazil concentrations increase near the ice shelf, flow in the near-shelf boundary layer becomes laminar as a result of frazil-induced viscosity increases and stable stratification, and our model predicts that a quasi-steady frazil distribution will form. In this state, frazil rising and a tiny ice growth balance precipitation onto the shelf and turbulent mixing of crystals back into the open plume. The precipitation rate predicted by our model (2.30) is determined by the relative magnitude of rising, diffusion and growth.

Sensitivity studies performed on the results from this plume section show that the value of $C(I)$ in the quasi-steady state depends upon the exact contribution of viscosity and stratification responsible for raising $R i$ to its critical value. This state may never be achieved if turbulence is strong enough to overcome frazil rising into the boundary layer. It was demonstrated how the quasi-steady precipitation rate and profile of frazil concentration throughout the upper plume are dependent upon both $C(I)$ and the balance of terms in the thin layer. Finally, it was shown that the uniform initial conditions employed throughout this paper give results that are qualitatively similar to simulations using results of SJ to provide initial conditions. At this particular location, the additional precipitation we predict seems to bring modelling estimates of basal accretion into line with rates inferred from observation.

The results from this modelling study show that frazil ice will be preferentially located toward the top of ISW plumes, with volume concentrations increasing towards a narrow layer near the ice shelf base. The study also elucidates the balance between turbulence and frazil dynamics that govern the deposition rate of frazil ice into an overlying boundary layer. These are both advances in our understanding of factors limiting the mass transfer rate of the ice pump mechanism.

We are extremely grateful to Adrian Jenkins, whose careful review of an earlier draft helped us to improve this paper significantly.

\section{REFERENCES}

Armenio, V. \& Sarkar, S. 2002 An investigation of stably stratified turbulent channel flow using large-eddy simulation. $J$. Fluid Mech. 459, 1-42.

Cantwell, B. J. 1981 Organised motion in turbulent flow. Annu. Rev. Fluid Mech. 13, 457-515.

DaLY, S. F. $1994 a$ Evolution of frazil ice in natural water bodies. In International Association for Hydraulic Research Working Group on Thermal Regimes: Report on Frazil Ice (ed. S. F. Daly), pp. 11-17. US Army Cold Regions Research and Engineering Laboratory, Hanover, New Hampshire.

DALY, S. F. $1994 b$ Frazil ice dynamics. In International Association for Hydraulic Research Working Group on Thermal Regimes: Report on Frazil Ice (ed. S. F. Daly), pp. 19-24. US Army Cold Regions Research and Engineering Laboratory, Hanover, New Hampshire.

Determann, J. \& Gerdes, R. 1994 Melting and freezing beneath ice shelves: Implications from a 3-D ocean circulation model. Ann. Glaciol. 20, 413-419.

Gerdes, R., Determann, J. \& Grosfeld, K. 1999 Ocean circulation beneath Filchner-Ronne Ice Shelf from three-dimensional model results. J. Geophys. Res. 104, 15 827-15 842.

Gosink, J. P. \& Osterkamp, T. E. 1983 Measurements and analyses of velocity profiles and frazil ice-crystal rise velocities during periods of frazil-ice formation in rivers. Ann. Glaciol. 4, 79-84.

Hammar, L. \& Shen, H. T. 1995 Frazil evolution in channels. J. Hydraul. Res. 33, 291-306.

Holland, D. M., Jacobs, S. S. \& Jenkins, A. 2003 Modelling the ocean circulation beneath the Ross Ice Shelf. Antarc. Sci. 15, 13, DOI:10.1017/S0954102003001019. 
Holland, D. M. \& Jenkins, A. 1999 Modelling thermodynamic ice-ocean interactions at the base of an ice shelf. J. Phys. Oceanogr. 29, 1787-1800.

Jeffries, M. O., Schwartz, K., Morris, K., Veazey, A. D., Krouse, H. R. \& Cushing, S. 1995 Evidence for platelet ice accretion in Arctic sea ice development. J. Geophys. Res. 100, 10 905-10 914.

Jenkins, A. \& Bombosch, A. 1995 Modelling the effects of frazil ice crystals on the dynamics and thermodynamics of Ice Shelf Water plumes. J. Geophys. Res. 100, 6967-6981.

Jenkins, A., Hellmer, H. H. \& Holland, D. M. 2001 The role of meltwater advection in the formulation of conservative boundary conditions at an ice-ocean interface. J. Phys. Oceanogr. 31, 285-296.

Jenkins, A. \& Holland, D. M. $2002 a$ A model study of ocean circulation beneath Filchner-Ronne Ice Shelf, Antarctica: Implications for bottom water formation. Geophys. Res. Lett. 29, 1193, DOI:10.1029/2001GL014589.

Jenkins, A. \& Holland, D. M. $2002 b$ Correction to 'A model study of ocean circulation beneath Filchner-Ronne Ice Shelf, Antarctica: Implications for bottom water formation'. Geophys. Res. Lett. 29, 1634, DOI:10.1029/2002GL015647.

Jeong, J., Hussain, F., Schoppa, W. \& Kim, J. 1997 Coherent structures near the wall in a turbulent channel flow. J. Fluid Mech. 332, 185-214.

Joughin, I. \& Padman, L. 2003 Melting and freezing beneath Filchner-Ronne Ice Shelf, Antarctica. Geophys. Res. Lett. 30, 1477, DOI:10.1029/2003GL016941.

vON KÁRmán, T. 1930 Mechanische ähnlichkeit und turbulenz. Nachrichten von der Geschellschaft der Wissenschaften zu Göttingen 5, 58-76.

LANE-SERfF, G. F. 1995 On meltwater under ice shelves. J. Geophys. Res. 100, 6961-6965.

Lewis, E. L. \& Perkin, R. G. 1983 Supercooling and energy exchange near the Arctic Ocean surface. J. Geophys. Res. 88, 7681-7685.

Lewis, E. L. \& Perkin, R. G. 1986 Ice pumps and their rates. J. Geophys. Res. 91, 11 756-11 762.

Marchioli, C. \& Soldati, A. 2002 Mechanisms for particle transfer and segregation in a turbulent boundary layer. J. Fluid Mech. 468, 283-315.

McCave, I. N. \& Swift, S. A. 1976 A physical model for the rate of deposition of fine-grained sediments in the deep sea. Geol. Soc. Am. Bull. 87, 541-546.

Newyear, K. \& Martin, S. 1999 Comparison of laboratory data with a viscous two-layer model of wave propagation in grease ice. J. Geophys. Res. 104, 7837-7840.

Nicholls, K. W. \& Jenkins, A. 1993 Temperature and salinity beneath Ronne Ice Shelf, Antarctica. J. Geophys. Res. 98, 22 553-22 568.

Nicholls, K. W., Makinson, K. \& Østerhus, S. 2004 Circulation and water masses beneath the northern Ronne Ice Shelf, Antarctica. J. Geophys. Res. 109, C12017, DOI:10.1029/2004JC002302.

NicholLS, K. W. \& Østerhus, S. 2004 Interannual variability and ventilation timescales in the ocean cavity beneath Filchner-Ronne Ice Shelf, Antarctica. J. Geophys. Res. 109, C04014, DOI:10.1029/2003JC002149.

Robinson, S. K. 1991 Coherent motions in the turbulent boundary layer. Annu. Rev. Fluid Mech. 23, 601-639.

SandhëGer, H., Vaughan, D. G. \& Lambrecht, A. 2004 Meteoric, marine and total ice thickness maps of Filchner-Ronne-Schelfeis, Antarctica. In FRISP Rep. 15 (ed. L. H. Smedsrud). Report Series from the Bjerknes Centre for Climate Research No. R14.

Smedsrud, L. H. \& Jenkins, A. 2004 Frazil ice formation in an Ice Shelf Water plume. J. Geophys. Res. 109, C03025, DOI:10.1029/2003JC001851.

Svensson, U. \& Omstedt, A. 1994 Simulation of supercooling and size distribution in frazil ice dynamics. Cold Reg. Sci. Technol. 22, 221-233.

Svensson, U. \& OMstedt, A. 1998 Numerical simulations of frazil ice dynamics in the upper layers of the ocean. Cold Reg. Sci. Technol. 28, 29-44.

Thyssen, F., Bombosch, A. \& SAndhäGER, H. 1993 Elevation, ice thickness, and structure mark maps of the central part of the Filchner-Ronne Ice Shelf. Polarforschung 62, 17-26.

Tritton, D. J. 1994 Physical Fluid Dynamics, 2nd edn. Oxford University Press.

Williams, M. J. M., Warner, R. C. \& BudD, W. F. 1998 The effects of ocean warming on melting and ocean circulation under the Amery Ice Shelf, East Antarctica. Ann. Glaciol. 27, 75-80. 